\title{
Intravenous labetalol vs. oral nifedipine in control of hypertensive emergencies in severe pre-eclampsia and eclampsia: a randomized control trial
}

\author{
Veena Devadiga $^{1 *}$, Veerendrakumar C. M. $^{2}$
}

\begin{abstract}
${ }^{1}$ Department of Obstetrics and Gynecology, Subbaiah Institute of Medical Sciences, Shimogga, Karnataka, India ${ }^{2}$ Department of Obstetrics and Gynecology, Vijayanagar Institute of Medical Sciences, Ballari, Karnataka, India
\end{abstract}

Received: 02 July 2021

Revised: 03 August 2021

Accepted: 04 August 2021

\author{
*Correspondence: \\ Dr. Veena Devadiga, \\ E-mail: veena2087@gmail.com
}

Copyright: ( $)$ the author(s), publisher and licensee Medip Academy. This is an open-access article distributed under the terms of the Creative Commons Attribution Non-Commercial License, which permits unrestricted non-commercial use, distribution, and reproduction in any medium, provided the original work is properly cited.

\begin{abstract}
Background: Pre-eclampsia is a disorder peculiar to human pregnancy and accounts for a considerable proportion of both maternal and perinatal deaths. This study was undertaken to compare the efficacy of labetalol versus nifedepine in the treatment of hypertensive crisis, maternal and fetal outcomes and also prevention of further complications in patients admitted to department of OBG, VIMS, Ballari.

Methods: Total 100 women with severe preeclampsia and eclampsia who were admitted in the labour room at the Vijayanagar institute of medical sciences, Ballari over a period ranging from April 2013 to September 2014 who fulfilled the inclusion and exclusion criteria were included in this Open Label, prospective, randomized study. Patients were allocated into two groups; group A and group B and managed with Intravenous labetalol and oral nifedipine respectively after proper history, examination and investigations.

Results: We found that less number of doses were required to achieve target blood pressure in labetalol group $(2.4 \pm 0.99)$ compared to nifedipine group patients who required more number of doses. $(2.56 \pm 0.84)$ Even with fixed dose regimen (VIMS Regimen) of labetalol, our study showed more rapid decrease in blood pressure to target level with labetalol group $(36 \pm 14.85 \mathrm{~min})$ compared to nifedipine group $(68.1 \pm 27.64 \mathrm{~min})$ which was statistically significant $(\mathrm{p}=0.000)$.

Conclusions: The goal of treatment is to maintain BP at a level that minimizes maternal cardiovascular and cerebrovascular risk. Labetalol is better than nifedipine in the management of hypertensive crisis in severe preeclampsia and eclampsia.
\end{abstract}

Keywords: Preeclampsia, Eclampsia, Labetalol, Nifedipine

\section{INTRODUCTION}

Haemorrhage and hypertensive disorders are major contributors to maternal deaths in developing countries. ${ }^{1}$ Hypertension in pregnancy is the second leading cause of maternal death, accounting for $20 \%$ of maternal deaths and presents an increased risk of complications for the fetus, including increased NICU involvement, preterm delivery and low birth weight and even fetal death. The studies have shown that early treatment of hypertensive crisis decreases not only the frequency of convulsions and associated maternal mortality and morbidity, but also the rate of neonatal complications.

Labetalol gives slow and steady (better) control of blood pressure compared to other antihypertensive agents. ${ }^{2}$ Advantage of labetalol is that, it is available as both injectable and oral and time of onset of action is earlier 
than Nifedipine. Nifedipine is easily available, cheap, and easily administrable and helps in rapid control of blood pressure. Since the literature of comparison of efficacy of these two drugs is scant in this part of the country, this study was undertaken to compare the efficacy of labetalol versus nifedepine in the treatment of hypertensive crisis, maternal and fetal outcomes and also prevention of further complications. Hypertensive disorders of pregnancy affect $5 \%$ of all pregnancies, $10 \%$ of first pregnancies and $20-25 \%$ of women with a history of chronic hypertension. $^{2}$ The term hypertensive crisis is defined as an elevation of the blood pressure to a degree which is potentially life-threatening and that requires immediate management in order to prevent end-organ damage. ${ }^{3}$

In eclampsia, the case fatality rate has been reported as $1.8 \%$ and a further $35 \%$ of women experience a major complication. ${ }^{4}$ The two main goals of management of women with severe preeclampsia during labour and delivery are prevention of seizures or eclampsia and control of hypertension. ${ }^{5}$ An effective anti hypertensive agent used is intra venous labetalol, an $\alpha$ land a non selective $\beta$ blocker for rapid control of blood pressure in severe pre eclampsia. It results in good and sustained control of BP. There is no tachycardia and BP is stabilized. Nifedipine is a $\mathrm{Ca} 2+$ channel blocker. A metaanalysis study done by Liu QQ et al in China on clinical efficacy and perinatal outcome of nifedipine for severe preeclampsia concluded that nifedipine is associated with greater effective control of blood pressure and prolongation of gestation, with no additional neonatal respiratory distress syndrome or perinatal deaths, compared with other antihypertensives for women with severe preeclampsia. ${ }^{11}$ Nifedipine effectively lowers blood pressure without any apparent reduction in uteroplacental blood flow. ${ }^{6}$ Oral nifedipine and IV labetalol equally effective for hypertension in pregnancy by Heidi Anne Duerr, MPH in 2012 concluded that "oral nifedipine and intravenous labetalol regimens are similarly effective in the acute control of severe hypertension in pregnancy. ${ }^{12}$

\section{Aim and objectives}

Aim and objectives of current research was to assess the time taken and the number of doses required to achieve target Blood pressure of $\leq 150 / 100 \mathrm{mmHg}$ in labetelol group and nifedepine group was the primary objective of this study. Secondary outcomes like maternal side effects and fetal side effects and feto-maternal outcome were also measured.

\section{METHODS}

In this open label, prospective, randomized study, the admitted patients in the labour room at the Vijayanagar institute of medical sciences, Ballari over a period ranging from April 2013 to September 2014 were recruited for the study.
A bilingual, written informed consent was obtained before the cases included as study sample. Pregnant females newly diagnosed with blood pressure of $>160$ / $110 \mathrm{mmHg}$ were included. Enrollment occurred antepartum, intrapartum and within 24 hours postpartum.

\section{Inclusion criteria}

Inclusion criterion for current study was; patients with severe preeclampsia/eclampsia and blood pressure of $>160 / 110 \mathrm{mmHg}$.

\section{Exclusion criteria}

Exclusion criterion for current study was; H/O cardiac disease, H/O bronchial asthma, H/O allergy to labetalol or nifedipine, siabetic, liver disorders, maternal heart rate $<60$ or $>120$ beats per minute, renal disease, connective tissue diseases.

\section{Selection of cases}

A total of 100 patients attending the above teaching hospitals were allocated to two groups by using computer generated sequence of random number. Group A: received injection labetalol, VIMS regimen (rule of 15) fixed dose regimen. Started with $15 \mathrm{mg}$ slow i.v. over 2 min and repeated $15 \mathrm{mg}$ every 15 minutes till the target BP achieved or upto15th dose. Patients who failed to achieve the target blood pressure even after the maximum dose received cross over regimen i.e. tablet nifedipine 10 mg every 30 minutes upto 8 th dose or till the target BP achieved. Group B: received tablet nifedepine. Started with 10mg orally and then repeated in fixed regimen fashion every 30 minutes till the target blood pressure achieved or upto 8th dose. Patients who failed to achieve the target blood pressure even after the maximum dose received cross over regimen injection labetalol $15 \mathrm{mg}$ every 15 min till the target BP achieved or upto 15th dose. Patient developing recurrences of hypertensive crisis after achieving target blood pressure was again given the same additional antihypertensive. Severe PIH was defined as a sustained systolic blood pressure of $>160 \mathrm{mmHg}$ and diastolic blood pressure of $>110 \mathrm{mmHg}$ on repeat measurement of 15 minutes apart in a lateral recumbent position with head of the bed elevation not exceeding 15 degree. Target BP to be achieved was $\leq 150 / 100 \mathrm{mmHg}$.

Injection $\mathrm{MgSo} 4$ was given to patients with eclapmsia in both group A and group B. A loading dose of $4 \mathrm{gm}$ of $50 \% \mathrm{MgSo} 4$ was given intravenously after diluting it in $20 \mathrm{cc}$ of $5 \%$ dextrose over $10-15 \mathrm{~min}$ and simultaneously, $4 \mathrm{gm}$ of undiluted $50 \% \mathrm{MgSo} 4$ was administered intramuscularly (single dose regimen). If convulsions occurred within 30 minutes of starting the therapy, no additional $\mathrm{MgSo} 4$ was given. If the convulsions were not controlled even 30 minutes after giving the single dose $\mathrm{MgSo} 4$, it was considered as a recurrence. These patients were switched over to Sardesai's low dose MgSo4 regimen i.e. $4 \mathrm{~g}$ of $\mathrm{Mgso} 4$ was given as a loading dose and 
thereafter, $2 \mathrm{~g}$ of $\mathrm{MgSo} 4$ (intramuscularly or diluted intravenously) was given as a maintenance dose every $3^{\text {rd }}$ hourly. Demographic and standard laboratory data were collected on admission. Once patients were enrolled, vital signs were recorded every 15 minutes, including blood pressure measurement until the woman is stabilized and then every 30 minutes in the initial phase of assessment by a mercury columns sphygmomanometer. The blood pressure cuff width was $15 \mathrm{~cm}$ and the length of the cuff was about 1.5 times mid arm circumference. Foetal monitoring was done by taking CTG trace at the beginning and then one at the end of the study/ two hours. Monitoring of the foetal heart rate and any abnormalities of it were noted. Maternal adverse effects like recurrence of convulsions in eclampsia patients, heart rate abnormalities, headache, nausea, dizziness were recorded. Fetal outcomes assessed by APGAR, meconium, NICU admission, Stillbirths, ENND etc. Patients were followed up till discharge.

Primary outcome measured in terms of number of doses and duration of the drug required to achieve the target blood pressure and secondary outcomes measured in terms of maternal morbidity and mortality and perinatal outcomes.

\section{Statistical analysis}

Statistical analysis was done by applying paired ' $t$ ' test for the difference in pre- and post treatment values. For inter group analysis, we applied Chi-Square test, using SPSS vs18 (statistical package for social sciences) statistical software version 3.3, $<<0.05$ was regarded as significant with $95 \%$ confidence limits.

\section{RESULTS}

In labetalol group $78 \%$ (39) of patients were 16 to 25 years of age group and $22 \%$ (11) patients were 26 to 35 years of age group. In nifedipine group $70 \%$ (35) of patients were 16 to 25 years of age group and $30 \%$ (15) patients were in 26 to 35 years of age group. The mean age group in labetalol group was $22.64 \pm 4.2$ years and in nifedipine group mean age group was 23.84 \pm 4 .1years (Table 1). In labetalol group $34 \%$ (17) of patients were multigravidae and $44 \%$ (22) of patients were multigravidae in nifedipine group. 66\% (33) of patients were primigravidae in labetalol group and $56 \%$ (28) of patients were in nifedipine group. So distribution based on obstetric data was not statistically significant in each group; $\mathrm{p}$ value $=0.611$ (Table 1$)$. Premonitory symptoms were seen in $46 \%$ (23) in labetalol group and $34 \%$ (17) in nifedipine group. Edema was seen in $82 \%$ (41) on patients in labetalol group and $90 \%$ (45) of patients in nifedipine group. In labetalol group $18 \%$ (9) of patients had anaemia and in nifedipine group $14 \%$ (7) had anaemia. In labetalol group $28 \%$ (14) of patients had altered consciousness and in nifedipine group 10\% (5) had altered consciousness. This was statistically significant $(\mathrm{p}$ value $=0.022)($ Table 1$)$.The mean systolic blood pressure was $180.16 \pm 11.42 \mathrm{mmHg}$ in labetalol group and $177.12 \pm 10.78 \mathrm{mmHg}$ in nifedipine group. It was not statistically significant ( $p$ value $=0.174)$. Mean diastolic was $123.20 \pm 8.33 \mathrm{~mm} \mathrm{Hg}$ in labetalol group and $120.88 \pm 7.16 \mathrm{~mm} \mathrm{Hg}$ in nifedipine group ( $\mathrm{p}$ value $=0.139$ ). The mean of mean arterial was $142.16 \pm 8.36 \mathrm{~mm} \mathrm{Hg}$ in labetalol group and $139.58 \pm 7.19 \mathrm{mmHg}$ in nifedipine group $(\mathrm{p}$ value $=0.101)($ Table 1$)$. The mean systolic blood pressure was $180.16 \pm 11.42 \mathrm{mmHg}$ in labetalol group and $177.12 \pm 10.78 \mathrm{mmHg}$ in nifedipine group. It was not statistically significant ( $\mathrm{p}$ value $=0.174$ ). Mean diastolic was $123.20 \pm 8.33 \mathrm{~mm} \mathrm{Hg}$ in labetalol group and $120.88 \pm 7.16 \mathrm{mmHg}$ in nifedipine group ( $\mathrm{p}$ value $=0.139$ ). The mean of mean arterial was $142.16 \pm 8.36 \mathrm{mmHg}$ in labetalol group and $139.58 \pm 7.19 \mathrm{~mm} \mathrm{Hg}$ in nifedipine group $(\mathrm{p}$ value $=0.101)($ Table 1$)$.

In labetalol group mean number of doses required to achieve target blood pressure was $2.4 \pm 0.99$ and in nifedipine group it was $2.56 \pm 0.84$ ( $\mathrm{p}$ value $=0.385)$. This was not statistically significant. The mean duration in minutes required to achieve target blood pressure was $36 \pm 14.85$ in labetalol group and $68.1 \pm 27.64$ in nifedipine group which was statistically significant ( $p$ value $=0.000$ ). Number of days to normalize BP was $2.2 \pm 0.70$ in labetalol group and $2.96 \pm 1.18$ in nifedipine group. It was statistically significant (p value $=0.000) \quad$ (Table 2). Recurrence of convulsions was seen in $4 \%$ (2) in labetalol group and in $18 \%$ (9) in nifedipine group which was statistically significant ( $p$ value=0.025). 4\% (2) required additional antihypertensives in labetalol group and $22 \%$ (11) in nifedipine group, which was statistically significant ( $\mathrm{p}$ value $=0.007)$ (Table 2$)$. In nifedepine group, $30 \%$ (15) of patients had side effects among them dizziness was seen in $4 \%$ (2) of patients and headache in $26 \%$ (13). In labetalol group 20\% (10) patients had side effects like dizziness in $4 \%$ (2) and nausea in $16 \%$ (8). This was statistically significant $(\mathrm{p}$ value $=0.000)($ Table 2).

Fetal distress was seen in $30 \%$ (12) of babies in labetalol group and $42.1 \%$ (16) of babies in nifedipine group, which was not statistically significant ( $p$ value $=0.479$ ) (Table 3). In labetalol group 20\% (10) were dead born and in nifedipine group $22.4 \%$ (11) were dead born. (Table 3). In labetalol group 80\% (40) were live born and in nifedipine group $77.6 \%$ (38) were live born. This was not statistically significant ( $\mathrm{p}$ value $=0.765)$ (Table.3). NICU admission was required in $32.5 \%$ (13) of live born babies in labetalol group and $47.4 \%$ (18) in nifedipine group, which was not statistically significant (p value $=0.181)($ Table 3$)$. In labetalol group $16 \%(8)$ were IUD, 4\% (2) were stillborns and $8 \%$ (4) had ENND. In nifedipine group $20.4 \%$ (10) were IUD, $2 \%$ (1) were stillborns and $18.4 \%$ (9) had ENND. This was not statistically significant $(\mathrm{p}$ value $=0.481)($ Table 3$)$.

Out of 17 in labetalol group who underwent $\mathrm{C} / \mathrm{S}, 1$ patient had PPH (5.9\%), no one had hypotension and 2 patients $(11.8 \%)$ had heart rate abnormalities. In 
nifedipine 4 patients had PPH (19\%), 6 patients had severe hypotension $(28.6 \%)$ and 9 patients $(42.9 \%)$ had heart rate abnormalities. The percentages of hypotension and heart rate abnormalities observed in nifedipine group were statistically significant ( $\mathrm{p}$ value $=0.019$ and 0.043 ) (Figure 1).

Table 1: Patient characteristics in different groups of study participants $(n=50)$.

\begin{tabular}{|c|c|c|c|c|}
\hline Variable & Parameter & Group A & Group B & $P$ value \\
\hline \multirow{2}{*}{ Age group } & $16-25$ & 39 & 35 & \multirow[b]{2}{*}{0.362} \\
\hline & $26-35$ & 11 & 15 & \\
\hline \multirow[b]{2}{*}{ Gravida } & Multi & 17 & 21 & \multirow[b]{2}{*}{0.305} \\
\hline & $\begin{array}{l}\text { Primi } \\
\text { Postpartum }\end{array}$ & 33 & $\begin{array}{l}28 \\
1\end{array}$ & \\
\hline \multirow{5}{*}{ Presence of symptoms } & Premonitory symptoms & 23 & 17 & 0.221 \\
\hline & Oedema & 41 & 45 & 0.249 \\
\hline & Signs of anaemia & 9 & 7 & 0.585 \\
\hline & Altered consciousness & 14 & 5 & 0.022 \\
\hline & Past $\mathrm{H} / \mathrm{O}$ convulsions & 5 & 10 & 0.161 \\
\hline \multirow{4}{*}{ Diagnosis } & Severe preeclampsia & 18 & 21 & \multirow{4}{*}{0.372} \\
\hline & Imminent eclampsia & 13 & 7 & \\
\hline & Antepartum eclampsia & 19 & 21 & \\
\hline & Post-partum eclampsia & 0 & 1 & \\
\hline \multirow{2}{*}{ Presence of complications } & HELLP syndrome & 8 & 11 & 0.444 \\
\hline & Abruption & 2 & 4 & 0.4 \\
\hline \multirow{3}{*}{ BP } & Systolic BP & 180.16 & 177.12 & 0.174 \\
\hline & Diastolic BP & 123.20 & 120.88 & 0.139 \\
\hline & Mean arterial pressure & 142.16 & 139.58 & 0.101 \\
\hline \multirow{2}{*}{ Blood parameters } & $\mathrm{Hb}<10 \mathrm{mg} / \mathrm{dl}$ & 17 & 14 & 0.517 \\
\hline & Platelets $<1.5$ lakh & 11 & 12 & 0.812 \\
\hline \multirow{2}{*}{ LFT } & Elevated liver enzymes & 2 & 4 & 0.4 \\
\hline & Raised LDH & 21 & 26 & 0.316 \\
\hline
\end{tabular}

Table 2: Distribution of patients based on the outcomes.

\begin{tabular}{|lllll|}
\hline Outcome & Indicator & Group A & Group B & P value \\
\hline \multirow{3}{*}{ Primary } & No. of doses & 2.4 & 2.56 & 0.385 \\
\cline { 2 - 5 } & Duration in min & 36 & 68.1 & 0.000 \\
\cline { 2 - 5 } & No. of days to normalize & 2.2 & 2.96 & 0.000 \\
\hline \multirow{2}{*}{ Secondary } & Recurrence of convulsion & 2 & 9 & 0.025 \\
\hline \multirow{3}{*}{ Side effects } & Need to use additional antihypertensive & 2 & 11 & 0.007 \\
& Dizziness & 2 & 2 & \multirow{2}{*}{0.000} \\
\cline { 2 - 4 } & Headache & 0 & 13 & \\
\cline { 2 - 5 } & Nausea & 8 & 0 & \\
\hline
\end{tabular}

Table 3: Foetal outcomes among the different groups.

\begin{tabular}{|c|c|c|c|c|}
\hline Outcome & Parameter & Group A & Group B & P value \\
\hline \multirow{2}{*}{ Fetal distress } & Presence & 28 & 22 & \multirow{2}{*}{0.479} \\
\hline & Absence & 12 & 16 & \\
\hline \multirow{2}{*}{ foetal outcome } & Dead born & 10 & 11 & \multirow{2}{*}{0.765} \\
\hline & Live born & 40 & 38 & \\
\hline \multirow{2}{*}{ NICU admission } & Yes & 13 & 18 & \multirow{2}{*}{0.181} \\
\hline & No & 27 & 20 & \\
\hline \multirow{3}{*}{ Perinatal mortality } & IUD & 8 & 10 & \multirow{3}{*}{0.481} \\
\hline & Still birth & 2 & 1 & \\
\hline & ENND & 4 & 9 & \\
\hline
\end{tabular}




\section{DISCUSSION}

The goal of treatment is to maintain BP at a level that minimizes maternal cardiovascular and cerebrovascular risk. SBP $>160 \mathrm{mmHg}$ was the most important factor associated with a cerebrovascular accident in patients with severe preeclampsia and eclampsia. Paulino VigilDe Gracia et al concluded that labetalol fulfills the criteria required for an antihypertensive drug to treat severe hypertension in pregnancy. ${ }^{13}$ Labetalol has been suggested as the first-line agent for hypertension accompanying stroke in preeclampsia, in the light of evidence that it lowers cerebral perfusion pressure without affecting cerebral perfusion. ${ }^{14}$ Our data supports recent guidelines and expert opinion that oral nifedipine and intravenous labetalol are suitable first-line antihypertensives for hypertensive emergencies of pregnancy. ${ }^{15}$

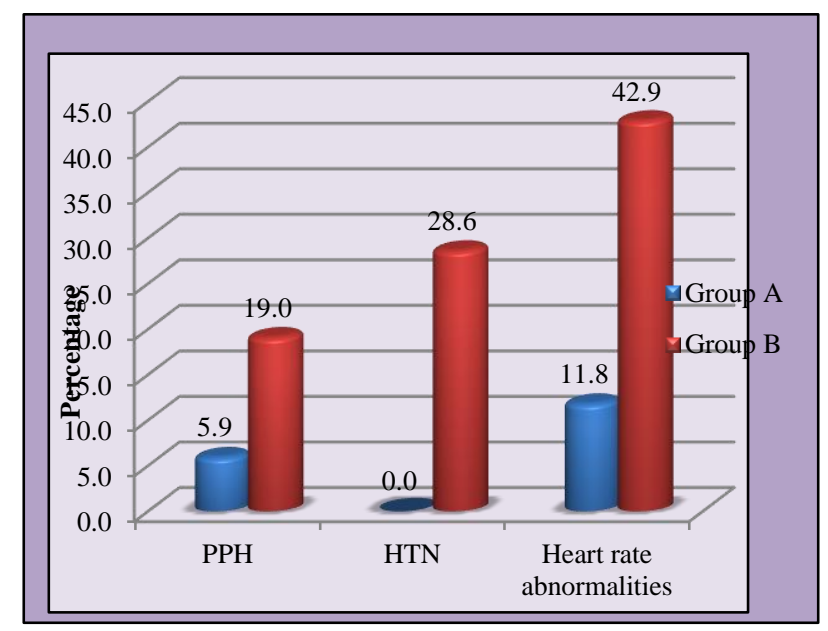

Figure 1: Intra operative complications in different groups.

In current study both the groups were demographically and characteristically comparable. Vermillion et al and Dhali et al studies have used $10 \mathrm{mg}$ of nifedipine initially followed by $20 \mathrm{mg}$ upto 5 doses every 20 minutes. $^{8-10}$ Where as in Raheem et al and Shekhar et al used fixed dose of nifedipine $10 \mathrm{mg}$ upto 5 doses. ${ }^{7,9}$ Other studies have used escalating doses of labetalol for hypertensive crisis. In our study we used fixed doses of labetalol (VIMS Regimen) and fixed doses of nifedipine. Yet the efficacy of labetalol was similar or even better than the results of other studies which is indicated by the less number of doses required to achieve target blood pressure in labetalol group $(2.4 \pm 0.99)$ compared to nifedipine group patients who required more number of doses $(2.56 \pm 0.84)$.

Even with fixed dose regimen (VIMS regimen) of labetalol, our study showed more rapid decrease in blood pressure to target level with labetalol group $(36 \pm 14.85$ min) compared to nifedipine group $(68.1 \pm 27.64)$ which was statistically significant $(\mathrm{p}$ value $=0.000)$. This outcome was in contrast with similar studies which showed that nifedipine more rapidly decreases blood pressure than labetalol. ${ }^{8,9}$ Raheem et al study indicates that both labetalol and nifedipine are equally effective in controlling hypertension in pregnancy. ${ }^{7}$

In current study number of days to normalize the blood pressure on follow up was less with labetalol group $(2.2 \pm 0.70)$ compared to nifedipine group $(2.96 \pm 1.18)$ which was statistically significant ( $p$ value $=0.000$ ) In other studies this secondary outcome was not measured. ${ }^{7-}$ 10 Our study showed recurrence of convulsions were more in patients who received nifedipine (18\%) compared to labetalol group of patients (4\%). This outcome was statistically significant ( $\mathrm{p}$ value $=0.025)$. This secondary outcome was not measured in other studies as patients with eclampsia were taken as one of the exclusion criteria in these studies. After extensive search in medscape we did not find any article to support this outcome. In our study out of 17 patients who underwent caesarean section in labetalol group, one patient had PPH and two of them had heart rate abnormalities i.e. bradycardia compared to 21 patients in nifedipine group 4 had PPH, 6 had hypotension and 9 had heart rate abnormalities i.e. profound tachycardia ( $p$ value $=0.518$ ). This outcome measure was not studied in other studies. ${ }^{7-10}$ Side effects profile was similar in both the groups in other studies except for one case of profound hypotension with nifedipine in vermillion study. ${ }^{7-10}$ In our study nifedipine group patients had more side effects than labetalol group ( $p$ value $=0.000$ ). There was no significant difference in the perinatal adverse outcomes like intrauterine fetal heart rate abnormalities, APGAR scores at 1 minute and 5 minutes, NICU admission and perinatal mortalities in both the groups. This finding is similar to the previous studies.

\section{Limitations}

Limitations of this study were small study group and observer bias as it was an open label randomised controlled trial.

\section{CONCLUSION}

Our study concludes that Labetalol is better than Nifedipine in the management of hypertensive crisis in severe preeclampsia and in eclampsia as it reduces the blood pressure more rapidly and constantly with better control on the recurrence of convulsions and ease of administration in altered consciousness. Labetalol is better than Nifedipine in terms of additional hypertensives required and number of days required to normalize the blood pressure and also with less side effects.

\section{Funding: No funding sources}

Conflict of interest: None declared

Ethical approval: The study was approved by the Institutional Ethics Committee 


\section{REFERENCES}

1. Khan KS, Wojdyla D, Say L, Gülmezoglu AM, Van Look PF. WHO analysis of causes of maternal death: a systematic review. Lancet. 2006;367(9516):10661074.

2. Mammaro A, Carrara S, Cavaliere A. Hypertensive disorders of pregnancy. J Prenat Med. 2009;3(1):1-5.

3. Bertel O, Conen D, Radü EW, Müller J, Lang C, Dubach UC. Nifedipine in hypertensive emergencies. Br Med J (Clin Res Ed). 1983;286(6358):19-21.

4. RCOG Guidelins. Available at: https://www.rcog.org. uk/guidelines. Accessed on 20 May 2021.

5. ACOG practice bulletin. Diagnosis and management of preeclampsia, andeclampsia. Obstet Gynecol. 2002;99(1):159-65.

6. Moretti MM, Fairlie FM, Axl S, Khoury AD, Sibai BM. The effect of nifedipine therapy on fetal placental Doppler waveforms in preeclampsia remote from term. Am J Obstet Gynecol 1990;163:1844-8.

7. Raheem I, Saaid R, Omar S, Tan P. Oral nifedipine versus intravenous labetalol for acute blood pressure control in hypertensive emergencies of pregnancy: a randomised trial. BJOG 2012;119:78-85.

8. Vermillion ST, James AS, Roger BN, Chauhan SP. Intravenous labetalol for acute blood pressure in pregnancy. Am J Obstet Gynecol. 1999;181:858-61.

9. Shekhar S, Sharma C, Thakur S, Verma S. Oral nifedipine or intravenous labetalol for hypertensive emergency in pregnancy: a randomized controlled trial. Obstet Gynecol. 2013;122(5):1057-63.
10. Dhali B, Shi DD, Yang FZ, Zhou L, Wang N. Oral nifedipine vs. intravenous labetalol for treatment of pregnancy-induced severe pre-eclampsia. J Clin Pharm Ther. 2016;41(6):657-661.

11. Liu QQ, Yu YH, Gong SP, Huang LP. Clinical efficacy and perinatal outcome of nifedipine for severe preeclampsia: meta-analysis. Zhonghua $\mathrm{Fu}$ Chan Ke Za Zhi. 2012;47(8):592-7.

12. Heidi AD. Oral nifedipine and IV labetalol equally effective for hypertension in Pregnancy. BJOG. 2012;45:52-9.

13. Vigil-De Gracia P, Lasso M, Ruiz E, Vega-Malek JC, de Mena FT, López JC; or the HYLA treatment study. Severe hypertension in pregnancy: hydralazine or labetalol. A randomized clinical trial. Eur J Obstet Gynecol Reprod Biol. 2006;128(1-2):157-62.

14. Martin JN Jr, Thigpen BD, Moore RC, Rose CH, Cushman J, May W. Stroke and severe preeclampsia and eclampsia: a paradigm shift focusing on systolic blood pressure. Obstet Gynecol. 2005;105(2):246-54.

15. Katzung BG. The ergot alkaloids. Basic and clinical pharmacology, Katzung, 10th ed. USA: McGrawHill; 2007:270-4.

Cite this article as: Devadiga V, Veerendrakumar CM. Intravenous labetalol vs. oral nifedipine in control of hypertensive emergencies in severe preeclampsia and eclampsia: a randomized control trial: Int J Reprod Contracept Obstet Gynecol 2021:10:3525-30. 